\title{
O ARQUIVO NA ESFERA VIRTUAL: ESPAÇO DAS DISCUSSÕES LITERÁRIAS 2000
}

\author{
Patrícia Pinheiro Almeida*
}

\begin{abstract}
RESUMO: O artigo "O arquivo na esfera virtual: espaço das discussões literárias 2000" tem por objetivo abordar possibilidades de registro e arquivamento de esferas/espaços de discussões literárias presentes nesse início de século XXI. Como bases rizomáticas, autores como Derrida, Deleuze, Barthes e Rebollar serão revisitados e servirão de apoio para a seleção de vestígios que seguirão para o direcionamento de pontos arqueológicos que possam alimentar 0 desenvolvimento desse recorte. $O$ estudo propõe releituras históricas sobre os lugares de alguns embates literários, em especial na França e no Brasil. Os espaços virtuais, embora descontínuos, podem almejar a construção de uma continuidade dessa discussão.
\end{abstract}

PALAVRAS-CHAVE: Arquivo. Virtual. Espaço. Discussão. Literatura.

Não há dúvidas, o mundo está sendo musealizado e nós todos temos algo a ver com isso. A meta parece ser a rememoração total

(total recall)

\section{Andreas Huyssen}

Angústia. Esquecimento. Permanência. Memória. Arquivo. Excesso. Necessidade. Compartilhamento. São perturbações, acredito eu, inerentes a muitos pesquisadores desse início de século, inseridos em uma esfera ${ }^{1}$ em que possivelmente 0 excesso e o aceleramento informacional evoquem a necessidade de uma memória permanente, de um arquivo ${ }^{2}$ duradouro. Desse modo, ao pensar este artigo, desejei formatar ideias, colocá-las em caixotes de pensamentos, determiná-las e catalogá-las, mas recuei, pois essa decisão

\footnotetext{
*Universidade Federal de Santa Catarina. Imeio: patvitara@hotmail.com.

${ }^{1}$ Esfera pública não é um espaço, mas um processo, a polêmica em si, a possibilidade da controvérsia e da existência, numa sociedade democrática, de uma esfera argumentativa. Falar de esfera pública é falar de um certo círculo hermenêutico produtor de sentido (hermenêutico que estuda a teoria da interpretação), mas cujos sentidos se constroem processualmente, na dinâmica incessante da circulação da informação (antes linear e hoje hipertextual). (SILVA, 2006.)

${ }^{2}$ Arquivo está relacionada à palavra Arkhê, que designa ao mesmo tempo o começo e o comando. Este nome coordena aparentemente dois princípios em um: o princípio da natureza da história ou da história, ali onde as coisas começam - princípio físico, histórico ou ontológico -, mas também o princípio da lei ali onde os homens e os deuses comandam, ali onde se exerce a autoridade, a ordem social, nesse lugar a partir do qual a ordem é dada - princípio nomológico. (DERRIDA, 2001)
}

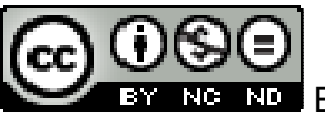

Texto Digital, Florianópolis, v. 9, n. 1, p. 3-23, jan./jul. 2013. ISSNe: 1807-9288 
poderia me levar a uma delimitação de um arquivo, poderia dar um sentido fechado a ele, uma imagem linear e isolada. E esse não era o meu intuito. Porém, era necessário buscar fragmentos, tomar decisões e trilhar um caminho, ou vários.

Definir o tema desse trabalho, "O arquivo na esfera virtual: espaço das discussões literárias 2000", onde eu poderia traçar possibilidades de encontrar os lugares dos salões literários online do início do século XXI, no Brasil, e tentar registrá-los, talvez de forma mais orgânica, impressa, por uma necessidade particular, me deu certo conforto a princípio, mas logo se seguiu ao retorno da angústia, do sofrimento e das dúvidas, que me levaram a novos questionamentos: Devo realmente definir um arquivo? A definição já não seria uma morte iminente? As minhas escolhas não vão cair no esquecimento? 0 papel é realmente palpável? O virtual não é palpável? Esse é o formato ideal para o registro? A palavra arquivo está sendo usada de forma correta nesse estudo? Novamente inquietações retomadas como um martelo na minha mente. E assim foi até permear ideias e caminhos que pudessem apaziguar, por instantes, "a impaciência absoluta de um desejo de memória" (DERRIDA, 2001, p. 9) de uma mulher inserida no contexto social contemporâneo, que almeja encontrar uma esfera que pudesse dar espaço ao ponto de discussão que "definiria" este projeto: o registro de parte dos salões literários 2000, contudo tomando às devidas precauções para não transformá-lo em um formato museológico tradicional, com uma ordenação pensada, um sistema fechado, isolado. Assim, dentre as minhas escolhas iniciais, vale ressaltar que ao optar pela palavra "arquivo", utilizada no título desse artigo e que provavelmente será retomada no decorrer desse estudo, não quis evocá-la forma pretensiosa, e sim por considerá-la pertinente para trilhar um percurso através das minhas leituras para que se possa caracterizar a ideia do "registro" de uma época em uma esfera e espaços a serem encontrados. 


\section{A memorização da História}

A transformação (como conceito de alteração na forma, e não necessariamente de melhoria) tem sido um processo constante e significativo no desenvolvimento humano no decorrer de sua caminhada. Assim, pode-se afirmar que o homem vive em frequente processo de transformação; e este, considerado como "processo civilizador" (ELIAS, 1993), está diretamente ligado à troca de conhecimento; uma troca que, por sua vez, pode ser percebida através das mais variadas formas, desde uma despropositada conversa até a formalização do conhecimento registrado em um livro. Porém, o conceito que se tem nos dias atuais com relação ao termo 'civilização' sofreu significativas transformações desde os séculos XVII e XVIII. Desse modo, tanto o significado do termo civilização quanto o conhecimento humano se transformaram, e continuam se transformando de acordo com a realidade vigorante do homem.

A História documenta que foram muitas as modificações no modo de construir e distribuir conhecimento. As necessidades primárias e imediatas, como se alimentar e se proteger, o incitaram a criar as primeiras armas de caça e as primeiras vestimentas de nossa história. Para conseguir alimentos e se abrigarem do frio e de predadores, eles também obtinham informações por meio do cheiro, da visão, da intuição e da observação do movimento da natureza (natureza esta que, por muito tempo, não foi questionada pelo homem, pois temia as manifestações dos deuses, como tempestades e doenças).

Outra necessidade dos ancestrais do homem, não menos importantes que as anteriores, mas que no desenvolvimento informacional, científico e tecnológico transforma cada vez mais a realidade do mundo, foi a de se comunicarem, o que os levaram a desenvolver as primeiras formas de expressão humana, como a mímica e os desenhos em cavernas. Após este período, a comunicação passa de oral à escrita e, como consequência, acarreta na multiplicação do conhecimento, por meio de registros, permitindo assim exteriorizar uma das funções pertinentes do cérebro humano: a memória. Essa, 
que nos dias atuais representa "a tentativa de diminuir o ritmo de processamento de informações, de resistir à dissolução do tempo na sincronicidade do arquivo, de descobrir um modo de contemplação fora do universo da simulação" (HUYSSEN, 1997, p. 18).

A História, em sua forma tradicional, empreendia 'memorizar' os monumentos do passado, transformando-os em documentos. Porém, em nossos dias, a História é o que transforma os documentos em monumentos. Desse modo, se volta para a descrição do monumento em um formato arqueológico, onde são buscados fragmentos em documentos que apontam para um momento ou uma época que possa ser revisitada e rememorada, para posteriormente transformá-los em monumentos, memória, arquivo. A análise literária passa a ser considerada na própria estrutura de uma obra, e não mais na sensibilidade de uma época, de uma geração ou de um movimento. "O problema não é mais da tradição e do rastro, mas do recorte e do limite" (FOUCAULT, 2008, p. 12). A história mudou sua posição em relação ao documento, que não é mais um instrumento de reconstrução onde se apresenta relevante interesse no que os homens disseram ou fizeram. A história procura definir, no próprio tecido documental, séries, relações e fragmentos que se voltam para a descrição intrínseca do monumento.

\footnotetext{
O documento não é o feliz instrumento de uma história que seria nela mesma, e de pleno direito, memória, a história é, para uma sociedade, uma certa maneira de dar estatuto de elaboração à massa documental de que ela não se separa (FOUCAULT, 2008, p. 12).
}

Nesse contexto, o arquivo passa a ser um grande dispositivo para a construção de uma memória, de uma identidade que se quer criar. Nele, toda ideia passa por um registro, que é passível de mudança. A questão central do arquivo é que ele está sempre no espaço da organização, porém em permanente construção. Essa organização, essa ordem, pressupõe a escolha, que é imposta enquanto leitura, e que ocupa lugar de destaque na definição de uma memória, de um monumento. 
O sentido do arquivo vem do arkheîon grego, que remete a endereço, domicílio, a residência dos magistrados superiores, os arcontes (aqueles que comandavam). Por sua importância, os arcontes ou regentes da Grécia antiga podiam deter em suas casas documentos oficiais. Assim, foram considerados os primeiros guardiões do arquivo, que também podiam ser interpretados por eles, considerados detentores da lei. Por serem mantidos em residências, os arquivos não tinham um suporte adequado de conservação, surgindo, assim, nessa domiciliação, a necessidade de um local adequado, uma morada. Essa morada, esse lugar marca a passagem institucional do espaço privado ao público, bastante presente na atualidade. Nos nossos dias, muitas casas transformaram-se em museus, a exemplo do Museu da República ou Palácio do Catete, no Rio de Janeiro, última morada de Getúlio Vargas. Ou, ainda, o museu do poeta Mário Quintana, em Porto Alegre, ou do pintor Vitor Meirelles, em Florianópolis.

Para Derrida (2001), não há arquivo sem o espaço instituído de um lugar de impressão, uma marca, uma cicatriz, que com um tempo vai mudando de espaço, podendo ser esse local externo, diretamente no suporte, ou virtual. 0 autor também destaca a necessidade do arquivista em exumar uma impressão, sendo um arquivista mais arqueólogo do que o próprio arqueólogo, exibindo "uma marca mais arcaica do que aquela com a qual se ocupavam os outros arqueólogos de todos os tipos" (DERRIDA, 2001, p. 126). Essa impressão não seria quase que um arquivo, mas se confundiria com a pressão do passo que deixa sua marca ainda viva sobre uma superfície de origem, e onde é possível vivê-la e revivê-la na sua singularidade, no momento em que a marca ainda não foi destituída pela pressão da impressão. "Um arquivo que se confundiria em suma com o arkhê, com a origem da qual ele não é contudo o tipo, o túpos, a letra ou o caráter repetível” (DERRIDA, 2001, p. 126).

Durante seu trabalho de escavação, para descrever o mal de arquivo em Freud, Derrida questiona-se em alguns momentos quantos às suas próprias escolhas, aos seus fragmentos, às suas seleções de registros. Para ele, nos dias de hoje, nada é mais perturbador que o conceito arquivado na palavra 
arquivo, nada é menos confiável que o termo arquivo, que reserva sempre um problema de tradução.

Singularidade insubstituível de um documento a interpretar, a repetir, a reproduzir, cada vez em sua unicidade original, pois um arquivo dever ser idiomático, e ao mesmo tempo ofertada e furtada à tradução, aberta e subtraída à iteração e à reprodutibilidade técnica (DERRIDA, 2001, p. 118).

Assim, o arquivo singular, que pode até ter um acervo finito, possibilita infinitas interpretações, infinitas escolhas, e infinitas combinações, que somente a leitura de cada um poderá definir. Na esfera virtual, por exemplo, em uma única página é possível ter milhares de combinações por meio de milhares de links, dependendo de quem os acessa, o que poderá levar o internauta às suas escolhas pessoais, às suas interpretações.

Considerando que o processo atual de registro de conhecimento está diretamente ligado ao uso que se faz desse conhecimento, a busca por informação em prol da produção de um arquivo para fixação de uma memória se transformou de forma significativa no decorrer da história da humanidade, ideia esta que nos remete a Coadic (1994), no momento em que ele diz que essas operações de multiplicação e memorização por meio de um registro palpável explicam uma boa parte do que se costumou chamar de explosão da informação (mais exatamente explosão da quantidade de informações).

\section{O desenvolvimento da linguagem literária e o seu compartilhamento}

Durante sua busca pelo conhecimento, após passar por desenhos em cavernas, símbolos e códigos, o homem conseguiu acumular um maior número de conhecimento por meio da escrita. Com sua evolução, porém, foi com o dispositivo da linguagem literária que o ser humano se assegurou na forma de compartilhamento de ideias. "A literatura, então, poderia ser definida como uma operação dentro da linguagem escrita que implica, em um mesmo movimento, vários níveis de realidade" (CAMPELO, 1998, p. 19). A cultura literária deu ao homem a capacidade de desenvolver um pensamento mais reflexivo e 
elaborado, ao contrário do caráter repetitivo inerente à cultura oral préliteratura. A capacidade de reflexão da cultura literária pode somar-se ao caráter mais espontâneo e repetitivo da oralidade. Assim sendo, uma obra marcada pelos efeitos da escrita também poderia explorar os efeitos da oralidade por meio das falas de alguns personagens, por exemplo.

Se em outros tempos, as pessoas precisavam treinar suas memórias para lembrarem-se das coisas, após a invenção da escrita elas tinham que treiná-las para lembrar-se de livros. Porém, os livros nada são se não forem lidos, se não forem interpretados, pesquisados, ou ainda remetidos a outras leituras, onde cada leitor tem seu próprio agenciamento. De acordo com Deleuze e Guattari (1995), o livro seria como um "corpo sem órgão" se não tiver em conexão com outros agenciamentos. Em um livro, existem linhas de articulações e segmentaridades, mas também há movimentos de fuga, de desterritorialização. "Tudo isso, as linhas e as velocidades mensuráveis, constitui um agenciamento. Um livro é um tal agenciamento e, como tal, inatribuível" (DELEUZE, 1995, p. 9). Desse modo, não se pode atribuir um livro a um objeto, a um sujeito. Se assim o for, negligencia-se todo o trabalho de exposição de suas correlações, suas interligações. "Fabrica-se um bom Deus para movimentos geológicos" (DELEUZE, 1995, p. 9).

Para Umberto Eco (1995), as conexões que os livros proporcionam desafiam e melhoram a memória; não a entorpecem. Porém, a inserção do livro na vida das pessoas não surtiu esse efeito sugerido por Eco instantaneamente após seu surgimento na história do homem, ela foi acontecendo de forma gradativa. A exemplo da Grécia antiga, a literatura pôde ser representada através do teatro - com sua cultura da oralidade - em inúmeras peças que fazem sucesso até os dias atuais, como é o caso Medeia, de Eurípides, ou Romeu e Julieta, de Shakespeare.

\footnotetext{
A literatura é coletiva, na medida em que requer uma certa comunhão de meios expressivos (a palavra, a imagem), e mobiliza afinidades profundas que congregam os homens de um lugar e de um momento, para chegar a uma comunicação (CANDIDO, 1985, p. 139).
} 
Com essa 'comunhão de meios', a literatura pôde se adaptar à evolução e à transformação de cada época. No Realismo, por exemplo, as obras procuravam 'imitar' a pintura, através de descrições pormenorizadas. Seguindo essa tendência, a fotografia, e principalmente o cinema também obtiveram importante sincretismo com a literatura. Além desses segmentos, a literatura representa também uma forma de registro de ideias e ideais de filósofos, cientistas, educadores, compositores, jornalistas, empresários, revolucionários, enfim, diversos segmentos da sociedade que tem a possibilidade de expressar seus pensamentos por meio da literatura. Ela tem sido, por todo esse tempo, uma das principais fontes de informação e comunicação para o conhecimento humano. Através da literatura pôde-se adquirir conhecimento, transmitir descobertas, viajar por mundos imaginários, e transitar por uma infinidade de novos paradigmas.

Com a evolução cultural e o desenvolvimento de recursos tecnológicos ocorridos no século XX e neste século XXI, tais como a imprensa, os discos, o rádio, o cinema e a TV, sem dúvida destaca-se a tecnologia digital. Aliada ao ambiente online, a literatura tem se adaptado com destreza a esse novo mundo de possibilidades, assumindo importante papel na era virtual, como também já havia assumido em outras épocas. Com o impacto da rede mundial de computadores, a forma de ler também foi profundamente alterada. As produções literárias estão agora intrínsecas nessa nova ordem mundial, onde a Tecnologia da Informação e Comunicação (TIC) assume papel de destaque e o homem se vê novamente inserido em um processo de adaptação com mais uma diferente forma de lidar com a leitura. Vale ressaltar que o processo de adaptação às novas tecnologias não é novidade para o homem no campo da literatura. O ser humano interage com as ferramentas tecnológicas para manifestar sua memória há bastante tempo. No início da civilização, ao usar o graveto e rabiscar a areia para registrar suas marcas para ser entendido ou, ao longo dos séculos, com o surgimento do alfabeto e da escrita, o homem já viabilizava a comunicação e a preservação de ideias através de ferramentas tecnológicas. 
Dos ambientes abertos da Grécia antiga, onde os diálogos de Platão eram ouvidos por todos, passando pela 'idade escura' do período medieval, momento em que o conhecimento era guardado a sete chaves - quando o conhecer e o saber ficam enclausurados e mistifica-se todo um processo de aprendizagem -, seguida das novas técnicas para duplicar a informação, como a criação da imprensa de Gutenberg, passando ainda pelo desenvolvimento da máquina de escrever, fazendo do teclado um objeto de distanciamento do contato do homem com o papel - o início de uma mudança radical de comportamento perante a literatura -, e chegando enfim ao mundo digital que elimina os limites de distância e espaço, as tecnologias incorporadas no cotidiano das pessoas a fim de preservar a memória e registrar suas ideias foram mudando de época a época, e a cada tempo de forma mais acelerada, mas sempre através da linguagem literária; ela que é a expressão, o investimento afetivo que define o homem de todas as épocas.

A evolução do conhecimento, que tem no surgimento da escrita sua primeira transformação na codificação das palavras - que se repete com o advento da internet -, também passa por outro tipo de transformação, que se refere à alteração comportamental do ser humano-leitor e, consequentemente, do ambiente intelectual literário, tudo isso para que houvesse uma melhor inserção nesse novo mundo virtual. No Brasil, o meio literário, que até certo momento da história, mais especificamente até 0 início do século $X X$, se mirava nos modelos de comportamento do velho mundo, sobretudo o francês, passa por uma transformação no final do período citado, em que o intelectual brasileiro se alia às novas tecnologias americanas para criar novas formas de conexão do meio, que no período de 1900 tinham nos salões literários seu mais significativo ponto de encontro literário, acrescido e substituído pelas salas de bate-papo, pelos sites de discussão e pelas comunidades virtuais.

Além da mudança da substituição de física para virtual dos locais de encontro literários, é de fundamental importância enfatizar a significância da grande mudança do formato literário devido ao aparecimento da rede mundial de computadores. Os locais físicos que representam atualmente a literatura no 
Brasil vêm se adaptando a esse novo molde, disponibilizando arquivos, que antes poderiam ser encontrados somente em formato de papel, como os livros, jornais, mapas e textos, e que agora passa a ser viabilizado também em formato digital.

\section{Leitor: ocupante de um ponto de vista}

O sujeito/leitor de Barthes é um sujeito desejante, inteiramente deportado sob o registro do imaginário; "toda a sua economia de prazer consiste em cuidar da sua relação dual com o livro (isto é, com a imagem), fechando-se a sós com ele" (BARTHES, 2005, p. 37). A leitura, para ele, é a condutora desse desejo, que faz com que o escritor, no seu desejo à escritura, deseje atingir o leitor enquanto escrita, desejando o 'ame-me' que está em toda escritura, traçando, assim, um elo de comunicação. Com isso, o trajeto do 'eu' escritor não é homogêneo, quando este se liberta do signo 'eu', o 'eu' é recebido pelo interlocutor com um signo estável, com conteúdos recorrentes. Desse modo, a escrita, e consequentemente a leitura, torna-se um ato sempre novo, formando uma interação entre escritor e leitor.

Toda prática de leitura busca, durante o seu percurso, chegar a um ponto em que se possa atribuir sentido ao texto. $E$ isso acontece de forma gradativa, sem pressa. O leitor é um navegador que descobre, ao longo do processo de leitura, sentidos, significados e inúmeras possibilidades de leituras que a obra the oferece, esta que não se apresenta por completo, mas se revela na medida em que o leitor intervém no seu trajeto. O leitor, com suas inúmeras facetas, pode ser identificado como um sujeito que circula e se apossa livremente do texto, criando, a partir de suas expectativas, suas próprias interpretações da obra, suas próprias produções de significados. Esse sujeito/leitor passa pelos paradoxos que acompanharam o desenvolvimento do ponto de vista do leitor e chega à imaginação de um leitor total - totalmente múltiplo e pragmático -, constituído de uma sobrecodificação hipertextual. Para Barthes, é onde se encontra o grande paradoxo da leitura que, com frequência, admite-se que ler é decodificar: letras, palavras, sentidos e estruturas. 
Mas acumulando as decodificações, já que a leitura é, de direito infinita, tirando a trava do sentido, pondo a leitura em roda livre (o que é sua vocação estrutural), o leitor é tomado por uma intervenção dialética: finalmente ele não decodifica, ele sobrecodifica; não decifra, produz, amontoa linguagens, deixa-se infinita e incansavelmente atravessar por elas: ele é essa travessia (BARTHES, 2005, p. 41).

Em Obra aberta, Umberto Eco propõe em 1989 um conceito de subcodificação, ocasião em que o leitor deve fazer uma leitura provisória do texto, e a sobrecodificação, que permite ao leitor escolher o subcódigo apropriado. Assim, o leitor estabelece uma interpretação criada a partir de um sobrecódigo por meio de uma ferramenta hipertextual, dando o ele um novo sentido à obra, que no caso da internet pode possibilitar uma maior interação entre o leitor e o autor, ou ainda entre leitores.

Com a web, surge também o desenvolvimento de recursos informáticos possíveis no ambiente digital, como o hipertexto virtual ${ }^{3}$, hoje um dos principais meios utilizados na web que possibilita uma leitura repleta de conexões, o que depende do olhar do leitor e do direcionamento do autor. Na obra impressa é possível encontrar facilmente algumas dessas técnicas mais utilizadas pelos escritores, como o emprego de notas introdutórias, dando uma conotação intertextual à obra, quadros hipertextuais e notas de rodapé, ambos podendo levar o leitor a outras leituras. Mas com a possibilidade de ferramentas disponíveis na web, essas técnicas ganham atualmente outras dimensões, podendo o autor ter um poder mais participativo na obra, e consequentemente o leitor. Por meio de suas hiperligações, o hipertexto virtual, hiperlink, ou simplesmente link, permite que o leitor elabore com mais facilidade, através de uma simples conexão, sua própria estratégia de leitura, percorrendo o caminho que achar mais conveniente.

\footnotetext{
${ }^{3} \mathrm{O}$ hipertexto virtual se caracteriza como um texto multidimensional em que, numa página, trechos de textos intercalam-se com referências a outras páginas. (MANDEL et alii. Informação: computação e comunicação. São Paulo, Revista da USP, número 35, 1997, pp. 10-45)
} 


\section{A necessidade da troca}

Neste início do século XXI, o internauta/leitor se torna ponto de referência para a vida literária 2000. Ele está adaptado a um novo mundo de possibilidades, no qual é possível adquirir quase de tudo pela internet. Periódicos, artigos, livros e textos em geral, diferentes linguagens, sinais e imagens passam a ser compartilhados por pessoas das mais variadas culturas e países. Um lançamento literário, por exemplo, pode ser disponibilizado hoje para venda ou leitura on-line com a maior comodidade. Acompanhando toda essa facilidade de aquisição de leituras, a web surge não só como uma importante fonte de informação, mas também como importante fonte de aproximação, devido à possibilidade da troca de conhecimentos. No campo literário, com todo o compartilhamento de textos em rede, o internauta/leitor passa a sentir a necessidade de dividir suas ideias e impressões literárias através da rede. Isso tudo através de uma linguagem nova, específica, com aspectos distintos da escrita tradicional e com características de interação oral. Através da Internet, surgiram novas formas de relacionamento e de contato com o outro, como a princípio o e-mail (correio eletrônico), o IRC (onde há canais/salas dedicados a diferentes assuntos que comportam um grande número de pessoas), o ICQ (programa de conversação em tempo real no qual os usuários se encontram através de seus números) e o MSN (similar ao ICQ, mas as pessoas aqui se encontram através de seus nomes). Segundo CHAGAS (2007), além de abreviações, variações no tamanho das letras, recursos visuais tentam suprir a ausência dos sinais corporais presentes numa interação face a face ou das inflexões de voz em uma conversa telefônica, como sinais gráficos, smileys ou emoticons, dentre outros. Para troca de informações gerais ou literárias, esses meios não são a única forma de compartilhamento no ambiente virtual.

Além dos variados sítios na web que fazem reflexões sobre textos, livros, escritores e vida literária, como o http://www.beatrice.com/wordpress/ e 0 (ambos americanos), http://portalliteral.terra.com.br, www.digestivocultural.com e http://www.jornaldepoesia.jor.br/agportal.htm (sítios brasileiros), o surgimento dos blogs, que a princípio eram tidos somente como 'diários íntimos', 
aumentaram a gama de possibilidades para o internauta interessado na troca de conhecimentos literários.

Chamada inicialmente de weblog 4 , conceito utilizado pela primeira vez em 1997 por Jorn Barger para sua página na internet www.robotwisdom.com (atualmente desativada), onde ele postava diariamente links de sítios que considerava interessantes, a palavra blog foi introduzida no ambiente virtual no início de 1999, "na sequência do anúncio de Peter Merholz, de que iria pronunciar o termo weblog como 'we-blog'” (CHAGAS, 2007, p. 3-5). No início, os blogs eram rudimentares em design e conteúdo, e era preciso muito habilidade com a Internet e com os softwares de programação para confeccioná-los. Foi a partir de 1999 que algumas empresas lançaram softwares para automatizar sua publicação. Uma dessas empresas, a Pyra Labs $^{5}$, lançou o software Blogger (www.blogger.com), que apresentava enorme facilidade para postagem de conteúdo e, com a sua interface privilegiando a escrita espontânea, foi adotado por centenas de pessoas. Este software popularizou a publicação de textos on-line, pois dispensava o uso de linguagens especializadas da computação, como a HTML, utilizada até então para a construção das páginas pessoais precursoras dos blogs.

O Blogger, que em 2000 lançou o permalink para garantir uma localização fixa, facilitando a divulgação dos posts (postagem), é até hoje um dos mais requisitados pelos internautas que querem iniciar um blog. Após este lançamento, alguns hackers criaram programas de comentários para os blogs, o que pôde ser considerado o início da mídia participativa na Internet. Esse processo significou a democratização da publicação e possibilitou que os leitores se transformassem também em escritores, acrescentando ou refutando uma informação. Outra característica do blog é a interatividade, pois o leitor pode fazer comentários sobre o que o 'blogueiro' escreveu, por e-mail contido no blog ou através de um link comments.

\footnotetext{
${ }^{4}$ Weblog tem sua origem na contração da palavra web (página na Internet) com a palavra log (diário de bordo).

${ }^{5}$ Disponível em: <http://www.abed.org.br/congress02005/por/pdf/026tcc5.pdf>. Acesso em: 19 ago. 2007.
} 
No Brasil, como em todo o mundo, existem blogs de todos os tipos, alguns com conteúdos banais, sem muita preocupação em conquistar visitantes, e outros com informações mais consistentes e que interessam um grande número de internautas, como é o caso dos blogs literários ou informativos, a exemplo do http://blogsembibliotecas.blogspot.com (sobre livros e leituras) e do www.pensarenlouquece.com (sobre política, cinema e literatura) e http://oglobo.globo.com/pais/noblat/. Apesar da qualidade de vários blogs como esses no País, muitos continuam em processo de transformação e precisam de mais atualizações, pois ainda existem alguns problemas, como a permanência dos sítios na Internet e dificuldades na seleção de páginas.

Além dos blogs como ambiente de compartilhamento de ideias, o usuário da web faz também do meio digital uma espécie de ponto de encontro virtual, que tem como intuito discutir com o internauta diversos temas propostos, através das chamadas listas de discussões - local no sítio onde várias pessoas podem deixar suas impressões sobre determinados assuntos proposto pela página. Para quem se interessa por literatura, este ambiente é bastante propício, pois existem listas que discutem diferentes temas da área, como 0 http://groups.yahoo.com/group/literatura// (lista de discussão literária espanhola que discute principalmente literatura ficcional, poesia e ensaio), o http://www.cavi.univ-paris3.fr/phalese/litor1.htm (lista francesa criada pelo escritor e professor de literatura Patrick Rebollar que discute literatura francesa e relação da literatura com o computador) e o http://www.nupill.org/ (um sítio brasileiro totalmente voltado para a literatura). Este último, além de possuir um vasto Banco de Dados de História Literária, da Biblioteca Digital de Literatura Brasileira, links para eventos da área, grupos de pesquisa, revistas de literatura em meio digital, conta também com o link Fórum, uma lista de discussão para debater temas de textos publicados por interessados em literatura em geral, eventos literários, literatura no meio digital e afim.

Integrados por um grande número de pessoas, sítios de relacionamento como MySpace e Facebook também oferecem um espaço para discussão de 
diferentes temas, inclusive literatura, através de grupos. A versão americana de MySpace possui 3.528 comunidades dedicadas a poetas, fotografias, escritores, teatro, clube de livros, Shakespeare, literatura clássica e artistas visionários.

Já o Facebook tem entre suas comunidades 500 grupos de discussão de literatura: os grupos brasileiros falam sobre escritores, Machado de Assis, Amigos de Recanto, Poesia Brasil; e em comunidades americanas discute-se literatura comparativa, literatura infantil, literatura russa, literatura clássica e literatura japonesa. Segundo REBOLLAR (2002), apesar de diversas pessoas participarem dessas listas de discussão, como escritores, universitários, jornalistas, eruditas e amadores, a grande maioria de críticos, professores e estudantes ignora os serviços que os computadores poderiam thes render ao penetrarem neste universo contemporâneo.

Existem ainda as salas de bate-papo ou chats, um tipo de ambiente acessado através de um sítio na internet que serve como uma sala virtual onde os assuntos são separados por temas. A comunicação só ocorre em tempo real e cada sala comporta, no máximo, 40 pessoas. Para entrar nessas salas, as pessoas têm que se cadastrar em um site específico, depois escolher uma sala e então iniciar a conversa, com um ou mais participante, para trocar informações on-line de mesmo interesse. Nos Estados Unidos, a sala de batepapo do site da escritora Maud Newton (http://www.maudnewton.com/) é bastante frequentada pelos interessados em literatura americana. No Brasil, um exemplo desse ambiente literário bem visitado está no sítio http://www.digestivocultural.com.br/ - terça-feira é o dia das críticas literárias. Mas como para esse tipo de acesso é preciso dispor de tempo para as conversas ou, o que acontece às vezes, no dia em que a pessoa está disponível os participantes da sala não são os mesmos que lhe interessavam noutro dia, esse espaço não é considerado o preferido pelos internautas em geral. 
O lugar na web que trouxe neste novo século uma maior liberdade e variedade de discussões, literárias ou não, são sem dúvida as comunidades virtuais. Estes locais estabelecem relações em um espaço virtual através dos meios de comunicação a distância no momento e lugar que a pessoa optar acessar, sem depender da anuência do outro para expor suas impressões. Outra vantagem desse ciberespaço é o fato de que nele é possível formar redes fixas de relações pessoais. Quando uma quantidade suficiente de pessoas leva adiante as discussões nas comunidades em que foram cadastradas é que se torna possível a formação dessas redes. Uma falha nas comunidades virtuais, como nos outros espaços virtuais, é fato do contato físico ser praticamente nulo. Algumas delas até tentam promover encontros e eventos fora do ambiente virtual como uma maneira de reforçar o contato tête-à-tête, como uma forma de poder complementar a relação social mantida no ciberespaço; mas como nem todos os internautas residem próximos uns dos outros esses encontros muitas vezes não alcançam seu objeto por falta de quórum.

Apesar da falta do contato pessoal, as comunidades virtuais proporcionam ao internauta se conectar com inúmeras pessoas dos mais variados lugares do mundo. Como as comunidades são desprovidas das barreiras de tempo, lugar e espaço (um dos principais fatores que potencializou sua criação - o que se deve ao uso das Tecnologias de Informação e Comunicação - TCI), seus integrantes podem expor com maior liberdade e frequência as mais variadas impressões sobre seus autores preferidos, por exemplo, e até mesmo incitar discussões às vezes bastante acaloradas, o que nos remete aos salões literários brasileiros do início do século XX, quando os literatos da época, como o passional escritor Silvio Romero ${ }^{6}$, defendiam suas convicções até o limite de suas forças.

\footnotetext{
${ }^{6}$ Todos os que provocavam discussões com Silvio Romero, ou que denegrisse a imagem de algum amigo seu, passavam a ser depreciados por ele. $O$ caso mais conhecido foi 0 violentíssimo ataque a José Veríssimo, divulgado em artigo, escrito em 1909, sob o título Zeverissimações Ineptas da Crítica (Repulsas e Desabafos). Of. do Comércio do Porto, Porto. 1909.
} 
Mesmo sem o contato físico, a vida literária nesse espaço on-line pode se tornar bastante intensa, quando internautas/leitores de todo o mundo dividem seus interesses comuns em um espaço interativo criado para servir como um novo tipo de organização social. A qualidade de conversação, de harmonia de espírito e de ordenação material do salão podem ser princípios aplicados, segundo REBOLLAR (2002), ao ambiente da internet. Na rede, as pessoas que nunca teriam a chance de frequentar os salões literários europeus tão famosos no século XVIII, têm na internet a oportunidade de estar virtualmente em um salão frequentado por indivíduos de diversas partes do planeta, claro que sem a mesma aura glamourosa dos salões daquele período, mas afinal, os tempos são outros.

\section{Considerações finais}

$\mathrm{Na}$ literatura contemporânea, a reconstrução da expectativa do leitor coincide com a objetivação dos padrões que orientam esse leitor, que demanda, talvez de forma inconsciente, uma mudança também no comportamento do autor, seja no meio impresso ou no virtual, que passa a utilizar com uma maior constância os recursos hipertextuais, tanto como processo quanto como objeto. O leitor não consegue mais se distanciar dessa interação, pois relaciona a obra uma situação pela atividade nele despertada. Se o leitor realiza os atos de apreensão esperado pelo autor e produz uma situação para o texto, sua relação com a obra não pode ser mais realizada por meio de uma divisão entre texto e leitor, entre doador e receptor. Por isso, também cresce a necessidade de compartilhamento de ideias acerca de temas literários e a ocupação dos espaços virtuais é iminente. Mas quais são esses os espaços que se pode caracterizar como lugares pertinentes de discussões literárias 2000? E para quem eles são pertinentes? Quem definirá esses locais como arquivos/registros a serem consultados? E esses registros estarão disponíveis virtualmente até quando? O papel aqui continuará sendo necessário para registrá-lo? Eles poderão vir a se tornar memórias de uma época? 
Ainda sem respostas para esses questionamentos, com esse artigo, deixo abertas as possibilidades de se pensar novas formas de registros das discussões literárias, para ilustrar novos paradigmas de um campo presente na realidade informacional do início do século XXI, indagando e colocando em diálogo vários movimentos arqueológicos.

Ao dialogar com a tradição e a contemporaneidade sem delimitar uma linearidade de leituras encontradas, sem compor regras de vestígios percebidos neste ou naquele autor, independente da sua época, tempo e espaço em que foi escrito, residiu aqui, por fim, uma tentativa em trilhar um caminho futuro para o registro de uma parte da memória de uma época.

\section{FILE IN THE VIRTUAL ESPHERE: THE 2000 LITERARY DISCUSSIONS' SPACE}

ABSTRACT: The article "File in the virtual sphere: the 2000 literary discussions' space" seeks to approach the possibilities of registration and filing of spheres/spaces of literary discussions present in this beginning of the XXI century. As rhizomactic bases, authors such as Derrida, Deleuze, Barthes and Rebollar will be revisited and will provide support for the selection of traces that follow for directing archaeological sites that can feed into the development of this crop. The study proposes historical rereadings about places of some literary collisions, especially in France and in Brazil. The virtual spaces, although discontinuous, can long for the construction of a continuation of this discussion.

KEYWORDS: File. Virtual. Space. Discussion. Literature.

\section{REFERÊNCIAS}

AGAMBEM, Giorgio. Signature rerum. 1 ed. Barcelona: Editorial Anagrama, 2010.

BARTHES, Roland. O prazer do texto. 4 ed. São Paulo: Perspectiva. 1996.

O rumor da língua. 2 ed. São Paulo: Martins Fontes, 2004.

S/Z. 2 ed. Rio de Janeiro: Nova Fronteira, 1992.

BAUDRILLARD, Jean. Simulacros e Simulação. 3 ed. Lisboa: Relógio d’Água, 1991.

BELLEI, Sérgio Luiz Prado. O livro, a literatura e o computador. 1 ed. Florianópolis, Editora UFSC, 2002. 
BEM, Isabela Vieira de; KIRCHOF, Edgar Roberto. O impacto da tecnologia sobre a literatura contemporânea. Florianópolis, Texto Digital, v. 2, n. 2, 2006. Disponível em: <http://www.periodicos.ufsc.br/index.php/textodigital/article/view/1372/1072>.

BENJAMIN, Walter. Obras escolhidas. Magia e técnica, arte e política. 7 ed. São Paulo: Editora 1994.

BLATTMANN, Úrsula; FRAGOSO, Graça Maria. O zapear a informação em bibliotecas digitais e na Internet. Florianópolis: Autêntica Editora, 2003.

BORGES, Jorge Luis. A biblioteca de babel. In: Ficções. São Paulo: Companhia das Letras, 2007.

CAMPELO, Bernadete S.; CALDEIRA, Paulo da T; MACEDO, Vera A. A. Formas e expressões do conhecimento - Introdução às fontes de informação. Belo Horizonte: Editora UFMG, 1998.

CANDIDO, Antonio. Literatura e Sociedade. Estudos de teoria e história literária. 7 ed. São Paulo: Companhia Editora Nacional, 1985.

CARVALHAL, Tânia Franco. Literatura comparada. 2 ed. São Paulo: Editora Ática, 1986.

COADIC, Yves-François Le. A ciência da informação. 3 ed. Brasília: Editora Gomes, 1994.

COSTA, Sely Maria de Souza. Impactos sociais das tecnologias de informação. Revista Biblioteconomia. Brasília, v. 19, n. 1, jan./jun. 1995. p. 3-22.

CHAGAS, Jurema. Blogs pessoais: a representação do eu na vida cibernética. 2007, 122p. Dissertação (Mestrado em Literatura) - Universidade Federal de Santa Catarina. Florianópolis. 2007. Disponível em: $<$ http://repositorio.ufsc.br/bitstream/handle/123456789/89768/243501.pdf?sequ ence $=1>$. Acesso em: 5 mai. 2013.

DALCASTAGNĖ, Regina. Quatro notas sobre a literatura na internet. In: Editora, 2001.

Estudos de Literatura Brasileira Contemporânea. Brasília: Brasília

DELEUZE, Gilles; Guattari Félix. Mil Platôs: capitalismo e esquizofrenia. 1 ed. Rio de Janeiro: Editora 34,1995.

DERRIDA, Jacques. Mal de Arquivo: uma impressão freudiana. 1 ed. Rio de Janeiro: Editora Relume, 2001.

ECO, Umberto. Da Internet à Gutenberg. 1996. Disponível em: <http://www.inf.ufsc.br/ jbosco/InternetPort.html>. Acesso em: 5 mai. 2013. 
. Obra aberta. 2 ed. São Paulo: Editora Perspectiva, 1989.

1995.

Os limites da interpretação. 3 ed. São Paulo: Editora Perspectiva,

ELIAS, Norbert. O processo civilizador. Formação do Estado e Civilização. 2 ed. Rio de Janeiro: Jorge Zahar Editora, 1993.

FOUCAULT, Michel. A arqueologia do saber. 7 ed. Rio de Janeiro: Forense Universitária, 2008.

GENETTE, Gerard. Palimpsestes: La littérature au second degré. 3 ed. Paris: Éditions du Seuil, 1982.

HOLANDA, Heloisa Buarque de. Vida literária na web. In: Jornal do Brasil, Ideias, 13/11/1999. Disponível em: <http://www.heloisabuarquedehollanda.com.br/vida-literaria-na-web/>. Acesso em: 5 mai. 2013.

HUYSSEN, Andreas. Memórias do modernismo. Tradução Patrícia Farias. Rio de Janeiro: Editora UFRJ, 1997.

LEVACOV, Marília. Bibliotecas Virtuais: (r)evolução? Revista Ciência da Informação, Brasília, v. 26, n. 2, 1997. Disponível em: $<$ http://revista.ibict.br/ciinf/index.php/ciinf/article/viewArticle/390>. Acesso em: 5 mai. 2013.

MANDEL et alii. Informação: computação e comunicação. Revista da USP, São Paulo, n. 35, p. 10-45, 1997. Disponível em: <http://www.ime.usp.br/ is/abc/abc/abc.html>. Acesso em: 5 mai. 2013.

MEIS, Leopoldo de. Ciência, Educação e o Conflito Humano-Tecnológico. 1 ed. São Paulo: Editora SENAC, 2002.

PARENTE, André. O virtual e o hipertextual. 2a ed. Rio de Janeiro: Editora Pazulin, 1999.

REBOLLAR, Patrick. Les salons littéraires sont dans l'internet. Presses universitaires de France, Collection Écritures électroniques, 2002.

SALES, Rodrigo de; ALMEIDA, Patrícia Pinheiro. Avaliação de fontes de informação na internet: avaliando o site do NuPILL/UFSC. Revista Digital de Biblioteconomia e Ciência da Informação. Campinas, v. 4, n. 2, p. 67-87, $2007 . \quad$ Disponível em: $<$ http://www.sbu.unicamp.br/seer/ojs/index.php/rbci/article/view/351>. Acesso em: 5 mai. 2013. 
SANTIAGO, Silviano. O Cosmopolitismo do Pobre.1 ed. Belo Horizonte: Editora UFMG.

2004.

SILVA, Luiz Martins da. Jornalismo, espaço público e esfera pública, hoje. Revista Comunicação e Espaço Público. Brasília, Ano IX, n. 1 e 2, 2006, p. 35-47. Disponível em: $<$ http://www.fac.unb.br/site/images/stories/Posgraduacao/Revista/Edicoes/2006 _revista.pdf>. Acesso em: 5 mai. 2013.

STAM, Robert. Teoria e prática da adaptação: da fidelidade à intertextualidade. Periódicos UFSC. Número 51, jul/dez de 2006. Florianópolis. 2006. Disponível em: $\quad<h t t p: / / w w w . p e r i o d i c o s . u f s c . b r / i n d e x . p h p / d e s t e r r o / a r t i c l e / v i e w / 9775>$. Acesso em: 5 mai. 2013.

WANDELLI, Raquel. Leituras do Hipertexto: Viagem ao Dicionário Kazar. $1^{\text {a }}$ edição. Florianópolis: Editora UFSC, 2003.

Texto enviado em maio de 2013.

Texto aprovado em julho de 2013. 